\title{
Varicella zoster virus reactivation during or immediately following treatment of tegumentary leishmaniasis with antimony compounds
}

\author{
Andrea Barbieri Barros ${ }^{1}$, Alex Miranda Rodrigues ${ }^{1,2}{ }^{+}$, Mariane Pereira Batista ${ }^{1}$, \\ Sidney Munhoz Junior', Marcia Hueb', Cor Jesus Fontes ${ }^{1}$ \\ 'Hospital Universitário Júlio Müller, Universidade Federal de Mato Grosso, Cuiabá, MT, Brasil \\ ${ }^{2}$ Faculdade de Medicina, Faculdade Presidente Antônio Carlos, Araguari, MG, Brasil
}

Antimony compounds are the cornerstone treatments for tegumentary leishmaniasis. The reactivation of herpes virus is a side effect described in few reports. We conducted an observational study to describe the incidence of herpes zoster reactivation during treatment with antimony compounds. The global incidence of herpes zoster is approximately 2.5 cases per 1,000 persons per month (or 30 cases per 1,000 persons per year). The estimated incidence of herpes zoster in patients undergoing antimony therapy is higher than previously reported.

Key words: leishmaniasis - herpes zoster - antimony therapy

Tegumentary leishmaniasis (TL) is a tropical parasitic disease with approximately one million estimated cases annually (Alvar et al. 2012). The most affected areas in the world are the Americas, the Mediterranean basin and western Asia, from the Middle East to Central Asia. In the New World, TL is caused by Leishmania (Viannia) braziliensis. Brazil is among the countries with the highest estimated number of cases (Alvar et al. 2012). In Brazil, the state of Mato Grosso (MT) comprises a large area of the country and cutaneous leishmaniasis is endemic in this state. The Tropical Infectious Diseases Unit of the Mato Grosso Federal University Hospital has been serving as a reference centre for the diagnosis and treatment of cutaneous leishmaniasis since the 1990s.

Globally, antimony compounds such as sodium stibogluconate and meglumine antimoniate are the first choices for the treatment of TL. This group of drugs has severe side effects that mainly affect cardiac, liver, muscle and metabolic functions. In 1966, herpes zoster was, for the first time, described in association with a treatment involving antimony compounds (Aslamazov et al. 1966). Herpes zoster, commonly known as "shingles", is a reactivation of the varicella zoster virus after becoming latent after a primary infection. The reactivation occurs mainly among the elderly and in immunosuppressed patients, including those with human immunodeficiency virus (HIV) infection and those using immunosuppressive drugs (Gnann \& Whitley 2012).

Since the first report of herpes zoster complicating antimony treatment for leishmaniasis (Aslamazov et al. 1966), new cases have been reported in Kenya, Belize and

doi: $10.1590 / 0074-0276130563$

+ Corresponding author: profalexmr@gmail.com

Received 6 December 2013

Accepted 2 May 2014
Peru and in American soldiers serving in the Middle East. Most of the reports involved isolated cases, with the largest series describing five cases (Hartzell et al. 2006). All of these cases were associated with the use of sodium stibogluconate (Chulay et al. 1983, Franke et al. 1990, Seaton et al. 1990, Wortmann et al. 1998, Hartzell et al. 2006).

The main objective of this paper is to describe the incidence of herpes zoster reactivation at a specialised clinic in Brazil.

A review of the medical records of patients treated for leishmaniasis between August 1994-May 2008 was performed at the Infectious Diseases Clinic of the Julio Müller University Hospital (Cuiaba, MT). The records were reviewed to obtain clinical and demographic data, including treatment options, associated illness, HIV infection and other causes of immunosuppression, and to evaluate the incidence of herpes zoster during antimony treatment or within a 90-day observation period after the completion of therapy. Complete data were available for 16 patients.

The Infectious Diseases Clinic uses antimony according to the doses and schedules recommended by the Brazilian Ministry of Health. For meglumine antimoniate, doses of $10-15 \mathrm{mg} / \mathrm{kg} / \mathrm{day}$ for 20 days are recommended for cutaneous leishmaniasis and $20 \mathrm{mg} / \mathrm{kg} / \mathrm{day}$ for 30 days is recommended for mucosal leishmaniasis (MS/FUNASA 2000). For sodium stibogluconate, doses of $10 \mathrm{mg} / \mathrm{kg} /$ day for 20 days are recommended for cutaneous leishmaniasis and $20 \mathrm{mg} / \mathrm{kg}$ /day for 30 days is recommended for mucosal leishmaniasis. Since 1997, the only antimony compound used in Brazil has been meglumine antimoniate (MS/FUNASA 2000).

The data were analysed using Epi Info v.6.04d (Centers for Disease Control, USA) and STATA 5.0 (Stata Corp, USA).

The study was approved by the Research Ethical Committee of Julio Müller University Hospital (099CEP-HUJM/2003). All data analysed in this study were anonymised and written consent was not required because the data were obtained from medical records, without any direct contact with patients. 
From 1994-2008, 2,137 cases of TL were treated and 16 cases of herpes zoster were identified in patients treated for cutaneous leishmaniasis with either meglumine antimoniate or sodium stibogluconate. In this case series, the median time to the appearance of shingles was 22.1 days (range, 8-36 days) after the beginning of antimony therapy. The cumulative probability of herpes zoster occurring after the start of antimony therapy is shown in Figure.

Most patients were young males living in rural areas, similar to most patients in Brazil (MS/SVS/DVE 2007). Four cases were associated with the use of sodium stibogluconate and 12 were associated with the use of meglumine antimoniate. At the time of the writing of this report, there were no other references to herpes zoster during or after use of meglumine antimoniate. The time between the start of antimony therapy and the appearance of herpes zoster, as well as the dose of elementary antimony received, were similar between patients who took either antimony drug (Table). Of the patients developing herpes zoster, 15 did not show any obvious cause of immunosuppression and only one was HIV positive. At the time of the appearance of herpes zoster, the HIVpositive patient had $93 \mathrm{CD} 4 \mathrm{~T}$ lymphocytes per $\mathrm{mm}^{3}$.

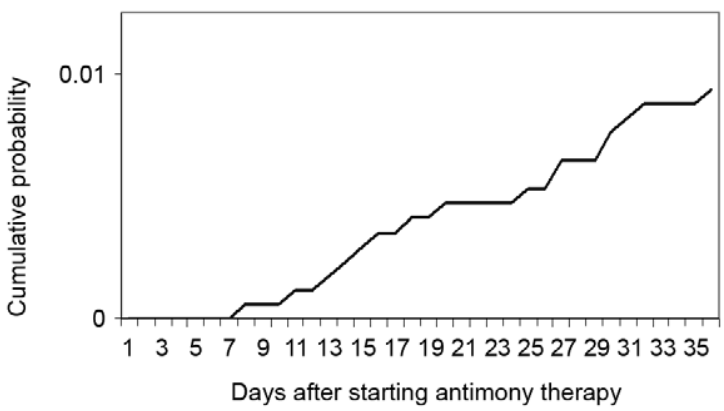

Cumulative probability of the development of herpes zoster during treatment with antimony compounds.

\section{TABLE}

Characteristics of patients with herpes zoster infection during the treatment of cutaneous leishmaniasis with antimony compounds

\begin{tabular}{lcc}
\hline Characteristics & $\mathrm{n}(\%)$ & $\mathrm{p}$ \\
\hline Sex & & \\
$\quad$ Male & $15(93.8)$ & - \\
$\quad$ Female & $1(6.3)$ & - \\
Age (years) [median (range)] & $53.3(22-81)$ & - \\
Drug & & \\
$\quad$ Meglumine antimoniate & $12(75)$ & - \\
$\quad$ Sodium stibogluconate & $4(25)$ & - \\
Human immunodeficiency virus infection & $1(6.3)$ & - \\
Time of appearance (days) [median (range)] & $22.1(8-36)$ & - \\
Meglumine antimoniate [median (range)] & $27.0(11-36)$ & 0.11 \\
Sodium stibogluconate [median (range)] & $16.5(8-20)$ & - \\
\hline
\end{tabular}

The mechanism of action of antimony compounds is still not completely understood. This group of drugs causes disruptions in cell division and/or cell signalling processes (Wortmann et al. 1998, Yoon et al. 2008) and may increase or decrease the number of $\mathrm{CD}^{+}$and $\mathrm{CD} 8^{+}$ T cell clones (Wortmann et al. 1998). Because there are few reports of herpes zoster infection during the use of antimony compounds in the treatment of TL, the association of these cases with a decrease in $\mathrm{T}$ cell counts or with transient immunosuppression induced by antimony treatment has not been established (Yoon et al. 2008).

Between 1998-2001, there were 6,247 incident cases of herpes zoster identified among active-duty United States of America (USA) service members, yielding a crude rate of 0.95 per 1,000 persons per month (Campbell 2002). Overall, the incidence of herpes zoster in the USA is 3.2 cases per 1,000 persons per year, reaching 10 cases per 1,000 persons per year for patients over 75 years of age and 14.5 cases per 1,000 persons per year for patients being treated with immunosuppressive drugs (Chakravarty 2008). Considering all TL patients treated at the Infectious Diseases Clinic during the study period and the recommended observation period of three months after drug interruption, the incidence of herpes zoster infection was approximately 2.5 cases per 1,000 persons per month (or 30 per 1,000 persons per year). However, for certain patients, the observation period was less than three months because they lived in rural areas, far from healthcare facilities. Thus, the actual incidence of herpes zoster infection among these patients could have been higher than that reported here. The incidence rate in this group of patients was high, especially because most of the patients were young adults. This fact reinforces the impression that there is a causal relationship between the use of antimony compounds for the treatment of TL and herpes zoster infection. Further research is necessary to improve our understanding of the mechanisms of the immune system disruption associated with these drugs, which results in the reactivation of latent varicella zoster infections.

In conclusion, this report describes more cases than the number of all published cases of herpes zoster infection that developed during the treatment of cutaneous leishmaniasis with antimony compounds. There are no previous reports of an association between herpes zoster and the use of meglumine antimoniate in the medical literature. The treatment of cutaneous leishmaniasis with antimony compounds appears to be a risk factor for reactivation of herpes zoster infection.

\section{REFERENCES}

Alvar J, Vélez ID, Bern C, Herrero M, Desjeux P, Cano J, Jannin J, den Boer M 2012. Leishmaniasis worldwide and global estimates of its incidence. PLoS ONE 7: e35671.

Aslamazov EG, Metel'skaia AO, Tumol'skaia NI 1966. Herpes zoster as a result of the toxic effect of antimony compounds on the organism. Med Parazitol (Mosk) 35: 600-601.

Campbell K 2002. Incidence rates and correlates of risk of herpes zoster, US Armed Forces, 1998-2001. MSMR 8: 2-5.

Chakravarty EF 2008. Viral infection and reactivation in autoimmune disease. Arthritis Rheum 58: 2949-2957. 
Chulay JD, Bhatt SM, Muigai R, Ho M, Gachihi G, Were JB, Chunge $\mathrm{C}$, Beyceson AD 1983. A comparison of three dosage regimens of sodium stibogluconate in the treatment of visceral leishmaniasis in Kenya. J Infect Dis 148: 148-155.

Franke ED, Wignall FS, Cruz ME, Rosales E, Tovar AA, Lucas CM, Berman JD 1990. Efficacy and toxicity of sodium stibogluconate for mucosal leishmaniasis. Ann Intern Med 113: 934-940.

Gnann JW, Whitley RJ 2012. Herpes zoster. N Engl J Med 347: 340-346.

Hartzell JD, Aronson NE, Nagaraja S, Whitman T, Hawkes CA, Wortmann G 2006. Varicella zoster virus meningitis complication sodium stiboglunate treatment for cutaneous leishmaniasis. Am J Trop Med Hyg 74: 591-592.

MS/FUNASA - Ministério da Saúde/Fundação Nacional de Saúde 2000. Manual de controle da leishmaniose tegumentar americana, 5th ed., MS, Brasília, 62 pp.
MS/SVS/DVE - Ministério da Saúde/Secretaria de Vigilância em Saúde/Departamento de Vigilância Epidemiológica 2007. Manual de vigilância da leishmaniose tegumentar americana, 2nd ed., MS, Brasília, 182 pp.

Seaton RA, Morrison J, Man I, Watson J, Nathwani D 1990. Outpatient parenteral antimicrobial therapy - a viable option for the management of cutaneous leishmaniasis. QJM 92: 659-667.

Wortmann GW, Aronson NE, Byrd JC, Grever MR, Oster CN 1998. Herpes zoster and lymphopenia associated with sodium stibogluconate therapy for cutaneous leishmaniasis. Clin Infect Dis 27: $509-512$.

Yoon IK, Cox J, Zhou Y, Lukes Y, Reinhardt B, Valencia-Micolta A, Wortmann G 2008. Varicella zoster virus-specific immune response after treatment with sodium stibogluconate for cutaneous leishmaniasis. Am J Trop Med Hyg 78: 402-405. 